\title{
Diversified Teaching Mode Reform of Mechanical Principle and Design Based on Internet Plus
}

\author{
Haining Gao ${ }^{1, *}$, Hongdan Shen ${ }^{2}$, Yinling Wang ${ }^{1}$ \\ ${ }^{1}$ School of mechanical and power engineering Huanghuail University, 463000, China. \\ ${ }^{2}$ Information Office HuanghuaiI University, 463000, China. \\ E-mail: 1013833276@qq.com
}

Abstract: As the first line of high-tech and new knowledge dissemination, teaching work should have the ability to adapt to the environment by quickly identifying new technologies, utilizing new technologies and popularizing new technologies. This paper directly points out the problems existing in the current teaching mode of mechanical principle course, and emphatically discusses the advantages of the new thinking and new technology content of the Internet in the teaching of mechanical principle and design, then puts forward the exploratory idea of the reform of diversified teaching mode.

Keywords: internet; mechanical principles and design; diversification; teaching

\section{Introduction}

Today's world is facing a revolution in learning, and we will thoroughly reform the old and traditional educational concepts and teaching models that have been used to for centuries, and create a new educational concept and learning model that truly respects human subjectivity and inspires creative belief and attention to the development of human potential and facilitates communication and cooperation. The concept of effective learning has undergone fundamental changes, and the focus of teaching research has shifted from how to teach to how to learn, from the result to the process, from mechanical practice to the understanding and application of knowledge. Students are no longer regarded as containers of acceptance of knowledge, but as builders and generators of knowledge.

Therefore, take the mechanical principle course as an example, with the help of the existing but not yet fully utilized technology means Internet technology, help students to actively acquire knowledge and awaken students' creative consciousness. The idea of this article is to abandon the monotonous and boring way of education in the classroom, that is, to let students memorize by rote, stiff formula, the meaning of this way is nothing more than to let students cope with the examination, get high marks in the examination, and not let them really meaningful to remember what they have learned and thought. We hope to help students understand that the knowledge learned in each class is interrelated and inseparable, and the depth and difficulty of knowledge are also progressive with each class. We hope that we can also cultivate students' keen insight, so that even if they only master one knowledge point at a time, they can expand and integrate this information in the later study, and then really master a subject. All in all, we hope to rekindle the fun of learning, that is, to let students actively participate in the process of learning and enjoy the natural excitement brought by learning, which is suppressed in the traditional classroom obedient education mode. Therefore, this paper proposes to integrate the thinking and practice from the Internet into the teaching mode of mechanical principles, and to form the teaching mode of mechanical principles course of thinking visualization, and at the same time to explore the reform direction of the underlying thinking and diversified teaching mode of deep cognition of mechanical principles

Copyright (C) 2020 Haining Gao et al.

doi: 10.18282/le.v9i5.1257

This is an open-access article distributed under the terms of the Creative Commons Attribution Non-Commercial License

(http://creativecommons.org/licenses/by-nc/4.0/), which permits unrestricted non-commercial use, distribution, and reproduction in any medium, provided the original work is properly cited. 
knowledge.

\section{Current problems in mechanical principle teaching}

\subsection{Teaching primarily}

In the traditional theory of mechanical principle and practical teaching, teachers dominate the whole teaching process, students study completely according to the teacher's teaching ideas, it is difficult to reflect the main role of students, cannot raise students' interest in learning, students' enthusiasm for learning is relatively low.

\subsection{Students study mainly in class}

At present, the learning mode of college students is mainly that teachers speak to students, and the capacity of learning courses on mechanical principles is limited. Teachers will feel that the class hours are not enough every semester, so they cannot supplement and extend some extra-curricular knowledge to students. Students' learning is mainly limited to a few minutes in the classroom, and students' extracurricular learning of mechanical principles is less time.

\subsection{The evaluation method of curriculum}

The traditional course evaluation adopts the combination of peacetime examination and final examination, and the comprehensive assessment method of independent record of experimental results. Final examination accounted for $70 \%$ to $80 \%$, the basic volume of the final grade. The way of course evaluation is relatively single, which reflects the students' initiative in extracurricular learning and the evaluation of learning effect is less, arouse the students' enthusiasm for curriculum learning. Figure 1 is a schematic diagram of the teaching structure of the mechanical principle course.

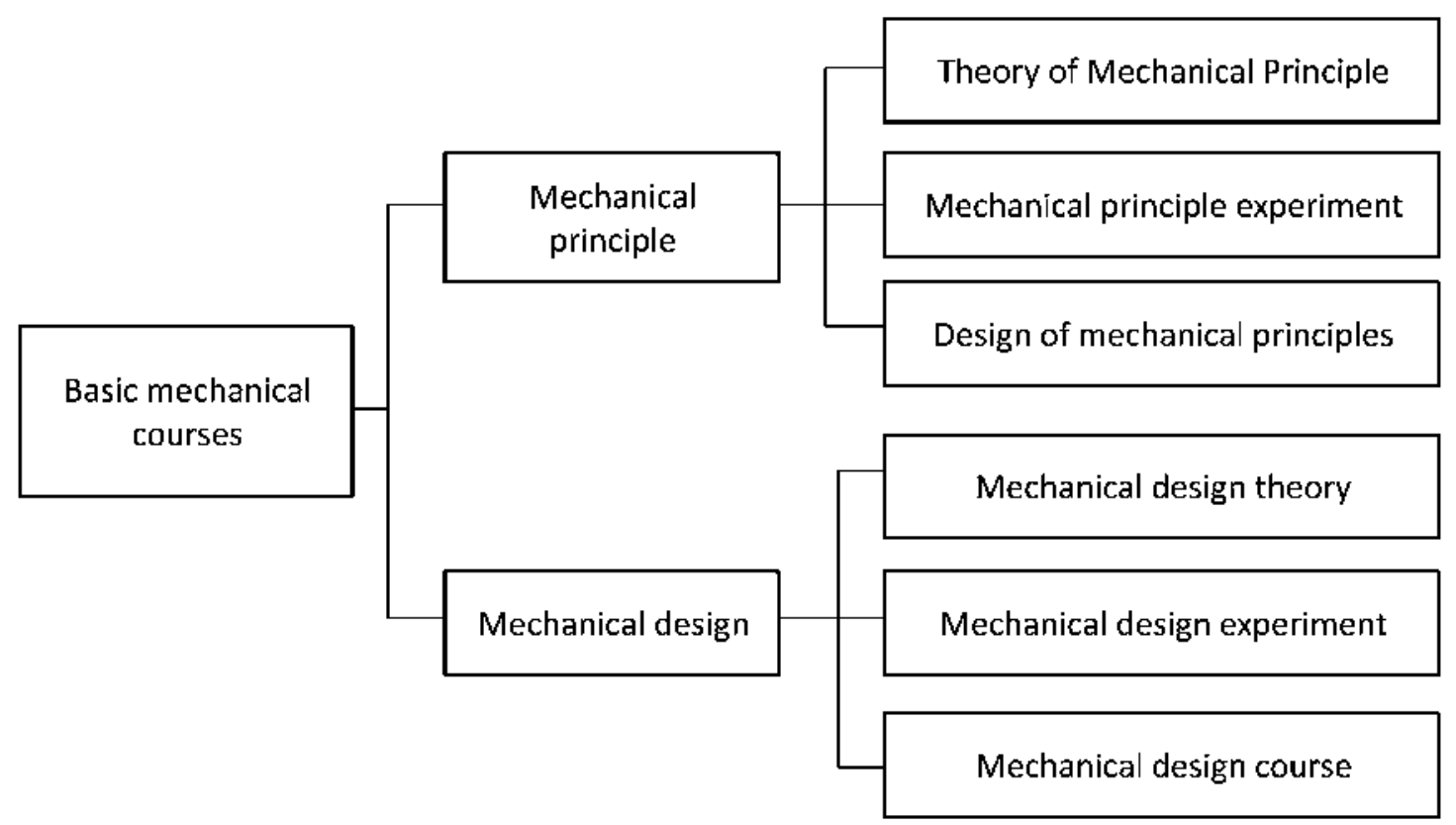

Figure1 Teaching Structure of Mechanical Principle Course

\section{Advantages of internet application in teaching mode of mechanical principle and design course}

\subsection{Internet literacy}

In analyzing the present situation of students' mechanical principle course, we can find that different students have different learning foundation and learning ability, and each student has different degree of knowledge mastery, which requires the formulation of appropriate teaching plan according to the teaching practice. When students learn difficult knowledge points in depth, the key is to make students fully master basic knowledge and concepts. In order to ensure that this cognitive process is reflected in the teaching practice of mechanical principles, it needs to be adopted. It is 
a kind of teaching method with the deepening of teaching reform. From the teaching practice of Internet proficiency teaching method, when the teaching conditions are fully prepared, the teaching process can be carried out smoothly, and the course teaching can meet the learning needs of each student. Under the action of this teaching method, the design of teaching content mainly considers the students' knowledge understanding degree and learning ability, and ensures the scientific and orderly development of mechanical principle classroom teaching. The combination of Internet technology and teaching practice is the key to ensure the effective implementation of sophisticated teaching methods, which provides favorable conditions for the teaching reform of mechanical principles. Under the traditional teaching environment, the innovation and implementation of teaching mode are limited, such as the high cost of teacher training and the high cost of printing paper materials. But the emergence and development of Internet of things, cloud computing and other technologies, has gradually formed a new teaching ecology, the future teaching methods are bound to change. Through the establishment of cloud service platform can record students' growth information to the platform, so as to ensure that teachers can carry out targeted teaching according to the characteristics of students, and can find teaching materials according to the actual needs of teaching.

\subsection{Reducing the difficulty of learning}

Mechanical principle course mainly includes mechanical power design, mechanism motion design and mechanical system design and so on. Some knowledge and concepts are unfamiliar to students, and it is difficult to learn for students without practical experience, which is the main reason that affects the quality of teaching. The application of mind map in course teaching can solve this problem well and promote the teaching reform of mechanical principle course. Mind map refers to the integration of multiple central themes to form a personal database, in the process of continuous curriculum teaching, gradually improve the students' personal database information, and then after the knowledge internalization into the students' own ability, to achieve the promotion of students' comprehensive ability. Therefore, it can be said that the use of mind map to comb and integrate the knowledge of mechanical principles plays an important role, which can deepen students' understanding of knowledge. Under the environment, we can use online learning resources to extend knowledge, which can provide students with rich teaching content. At this time, students need to find suitable learning methods for themselves which connect knowledge and make summary analysis, so as to improve the teaching quality.

\section{The reform of the diversified teaching mode of internet plus mechanical principle course}

\subsection{The theory teaching adopts the flipping classroom teaching mode}

Internet teaching mode makes it possible to adopt the flipped classroom characterized by learning first and teaching later. In mechanical principle teaching, teachers and students interact through the network, which can completely break through the space-time limit in the classroom. Students can communicate with their classmates and teachers anytime, anywhere. During online open courses and mobile phone APP network communication, the leading role of teachers has reached the highest limit, and teachers can give students answering questions and learning guidance at any time through mobile terminals. Teaching teachers no longer just instill knowledge to students, more is to provide links to learning resources, stimulate students' interest in learning, and carry out innovative thinking and logical thinking guidance. The teaching of the teacher's curriculum will become more comfortable, teaching means more colorful. Students can learn what they want to learn in class, through the animation and sound of the image in the network course to solve the learning doubts in the heart will greatly improve the students' learning initiative and enthusiasm.

\subsection{Adjustment of the contents of theoretical teaching courses}

Mechanical principles online open courses with course content video teaching, students can learn through the network after class. In this way, teachers in the classroom theory teaching, students can self-taught part of the curriculum content cannot be said or simply explained. In this way, when the teaching hours are constant, the corresponding teaching contents can be adjusted to increase the relevant curriculum contents to improve the students' innovative ability and engineering practice ability. Add the teaching content about the design of common mechanism, especially 
the design of plane linkage mechanism, mechanical system scheme design, combination mechanism design and so on, so as to improve the students' innovative ability. Add application engineering examples of commonly used institutions in practical practice. At the same time, some engineering application examples of mechanical system design are hung into the online course, so that students can use their spare time to study online, expand their professional knowledge, and improve their engineering practice ability and innovation ability. At the same time, it provides students with some design questions of mechanical principle, and let students use the 3D entity software to design the mechanism system after class, which will greatly improve the students' ability of institutional synthesis and mechanical system scheme design. Figure 2 is the framework of integrated cloud platform theory teaching system for Internet teaching mode.

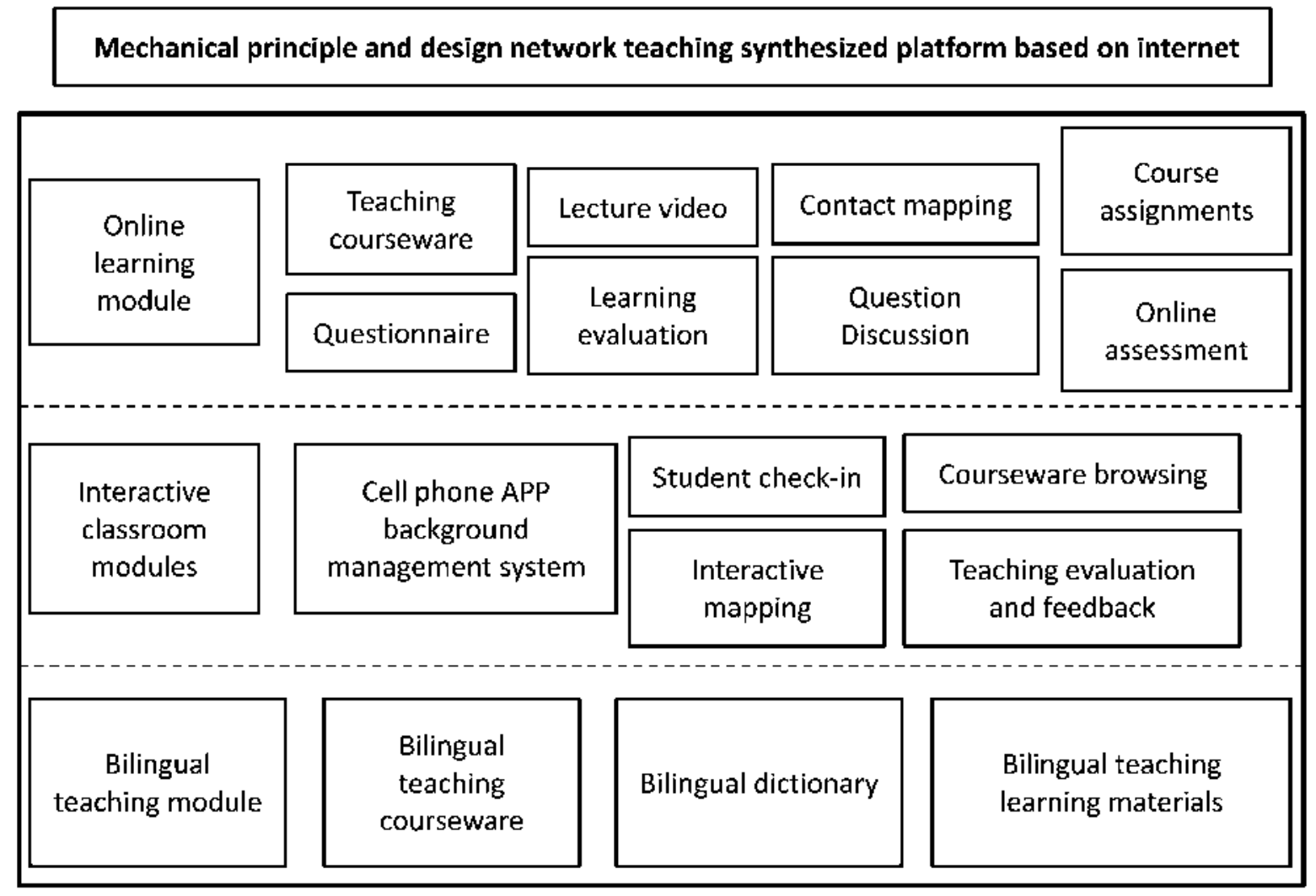

Figure 2 Framework of Integrated Cloud Platform Theory Teaching Link for Internet Teaching Mode

\subsection{Reform of experimental teaching content}

The traditional cognitive experiment of typical mechanism, mapping and analysis of mechanism motion diagram and machining principle of gear tooth profile can be carried out in online course. The experiment module of online course can realize dynamic simulation of mechanical model, drawing of mechanism diagram and machining experiment of gear principle. The mechanism model is displayed by the combination of physical photos and mechanism dynamic simulation. The image is intuitive, and it can also avoid the damage to the mechanism model in the actual operation of the laboratory. Students can draw the mechanism diagram by themselves according to the given mechanism model and submit it online. The machining experiment of gear Fan Cheng principle can input the corresponding gear parameters according to the need, and generate the required gear contour line according to the gear Fan Cheng principle, and the students carry on the experimental analysis according to the figure. These experiments allow students to use their spare time to complete, not only do not occupy the experimental class time, but also improve the students' autonomous learning ability and practical ability.

On the basis of conventional experiments, we set up creative design experiments of planar mechanism, flexibly use the combination of mechanism, mechanism evolution and variation, creatively design and splice the mechanism; enhance students' perceptual understanding of the organization, cultivate students' engineering practice and practical ability; complete the transition from motion diagram design to actual structure design. At the same time, open experiments, open laboratories, encourage students to independently design mechanical devices and carry out analysis, 
enhance students' practical and analytical ability; cultivate students' engineering practice ability. Encouraging and guiding mechanical students to participate in all kinds of scientific and technological innovation competitions can not only make students get credit and reward for innovation in the school encouragement policy, but also improve students' ability of innovation and practice, and improve students' enthusiasm for learning.

\section{Conclusion}

This paper takes the mechanical principle and the mechanical design course as the teaching reform object, aiming at the course theory teaching link, the experiment teaching link and the practice training link, has constructed a set of multi-level, the diversification teaching pattern and the system with the Internet technology as the core based on internet plus. Mechanical principle and design of network teaching comprehensive cloud platform effectively mobilize students' interest and enthusiasm in learning, improve the overall effect and quality of curriculum teaching.

\section{References}

1. Zhong Wen. Exploration on Teaching Reform of Mechanical Principle Course [J]. New Curriculum Reform and Practice ,2010:1-1.

2. Zhang Yan. . Internet education. Ideas and Patterns [J].China Higher Education Research ,2016(2)70-73.

3. Wu Zhaoyun, Ma Xiaolu, Li Li, et al. A Reform of Mechanical Principle and Design Diversified Teaching Mode Based on Internet [J].Higher Education Journal ,2019,000(014):75-77.

4. Zhao Yongjie, Cheng Xiyun. Exploration and Reform of Inquiry Teaching in Mechanical Principle Course [J]. University Education ,2014 000(009):141-143.

5. Liu Qiong, Zhu Yaguang, Hui Ji Zhuang, et al. . Internet. A Study on the Reform of Teaching Mode of Mechanical Principle Course [J].Education and Teaching Forum ,2018.

6. Wang Xiaorong. . Internet teaching. Discussion on Teaching Reform of Mechanical Principle Course [J].Shaanxi Education (Higher Education),2019.

7. Ding Ruihua. Reform and Practice of Mechanical Principle Course Teaching under the Training Mode of Applied Talents [J].Mechanical Management Development ,2017,32(8):76-78 